\title{
A Study on Technology Acceptance of Elderly living Alone in Smart City Environment: Based on AI Speaker
}

\author{
Hyun-Sil YOO*, Eung-Kyo SUH**, Tae-Hyung KIM*** \\ Received: January 24, 2020 Revised: January 30, 2020 Accepted: February 05, 2020.
}

\begin{abstract}
Purpose: This study is to examine the intention of the elderly who live alone in the customized AI speaker for the elderly living alone to improve the quality of life service for the elderly living alone in the smart city environment. Based on the quality of life model of the elderly, this study is applied to the technology acceptance model to investigate the relationship between perceived usefulness and ease of use on the sustained use intention. Research design, data and methodology: Residents in Suwon, Gyeonggi-do, selected as candidate local governments for the Smart City Challenge Project of the Ministry of Land, Infrastructure and Transport in June 2019 to measure the perceived technology acceptance of potential users for the AI technology for the elderly living alone as part of the smart city technology. In order to evaluate the intention of using AI speaker, which is the target system of this study, a video of a chatbot using experience of elderly people living alone was produced. Results: First of all, in order for the elderly living alone to have an attitude to use AI-based speakers, there should be a perceived usefulness of the quality of life of the elderly. However, ease of use did not show any significant causal relationship to attitude toward use. In addition, the attitude toward use weakly influenced the intention to use. In other words, elderly people living alone were not likely to have a significant effect on their attitude toward use. However, feeling that AI speakers are easy to use will help to improve the quality of life, which in turn led to the attitude toward using AI speakers, which could lead to indirect effects. Finally, the perceived usefulness of quality of life was found to have a weak effect on direct use intentions. Conclusions: This study conducted a study on the technology acceptance of service environment to improve the quality of life for the specific user group who live alone in the smart seat environment. In this study, we examined the effects of AI speaker on the elderly living alone to improve the quality of life for the elderly living alone.
\end{abstract}

Keywords : Smartcity, AI Speaker, GQOL, Elderly living alone, Technology acceptance model

JEL Classification Code : I19, M15, L86.

\section{1. 서론}

최근 우리 사회의 고령화 속도는 매우 빠르게 진행되고 있다. 2019년 고령자 통계에 따르면, 65 세 이상 인구는 전체 인구의 $14.9 \%$ 이며, 2060 년에는 전체 인구의 43.9\%를 차지할 것으로 전망되고 있다. 특히 고령 인구의 급속한 증가, 젊은 가족들의 노인 부양에 대한 의무감 약화,

\footnotetext{
* First Author. Professor, Department of Counselling, Dankook University, Korea, Email: hsyoo@dankook.ac.kr

** Professor, Graduate school of Business, Dankook University, Korea, Email: eungkyosuh@dankook.ac.kr

${ }^{* * *}$ Corresponding Author. Professor, Department of Data Science, Graduate School, Dankook University, Korea, Tel: +82-31-80053981, Email: kimtoja@dankook.ac.kr (c) Copyright: Korean Distribution Science Association (KODISA)

This is an Open Access article distributed under the terms of the Creative Commons Attribution NonCommercial License (https://creativecommons.org/licenses/by-nc/4.0/) which permits unrestricted noncommercial use, distribution, and reproduction in any medium, provided the original work is properly cited.
}

고령자의 이혼 증가 등 사회적 변화로 독거노인 인구는 더욱 빠르게 증가하고 있다. 독거는 개인적, 사회적, 경제적 등 다양한 이유로 개인이 선택하는 거주 형태이면서도 개인의 정신 건강과 사회적 관계의 질에 강력한 영향을 미치는 요인으로 알려져 있다(Nam \& Jung, 2011). 특히, 노년기의 독거는 이혼, 배우자와의 사별, 자녀의 독립, 불화 등 가족 구조의 변화로 인해 선택 되어진 거주 형태의 하나로, 동거인의 부재와 사회적 지지체계의 결핍은 고령자의 신체적 기능의 상실과 일상생활의 어려움을 더욱 가중시키며, 정서적 단절과 사회적 관계의 질 악화로 인해 심리사회적 건강을 해치는 등 노년기의 삶의 질을 크게 떨어뜨린다(Nzabona, Ntozi, Rutaremwa, 2016; Russell \& Taylor, 2009). 따라서, 고령화 사회의 주요한 이슈로 떠오르고 있는 독거노인 문제와 관련하여 노년기의 신체적, 정신적, 사회적 기능을 유지하고, 이를 통해 
독거노인의 삶의 질을 향상시킬 수 있는 보다 적극적 노력이 필요한 시점이다.

4 차산업혁명시대의 기술은 도시에 적용되기 시작하였다. 모바일, 인공지능, 사물인터넷, 빅데이터, 자율주행자동차, 드론 등의 기술과 제품이 등장함에 따라 기존의 도시환경과는 완전히 다른 스마트시티가 나타나고 있다. 스마트시티 환경에서 사람들은 첨단 기술기반의 서비스를 제공받게 되는데 교통, 의료, 경제, 주거 등 시민들의 일상생활과 밀접한 모든 분야에 해당된다. 이렇듯 기술의 발달과 더불어 다양한 요소기술들을 바탕으로 제작된 다양한 스마트시티 기반의 기술들은 사람들에게 생활의 편리함을 가져다 준다. 하지만 일부 취약계층의 사람들에게는 여전히 어려움이 존재하는 것이 현실이다. 고령자의 경우 스마트폰, 스마트워치 등은 화면이 작고, 터치가 불편해 활용도가 낮은 것이 현실이다.

최근 각광받고 있는 인공지능의 기술은 이러한 문제해결의 실마리가 될 수 있다. 음성인식기술 기반의 인공지능 스피커는 음성을 기반으로 정보기기와 사람이 상호작용을 함으로써 기존의 터치나 키보드 입력방식에 비하여 더 빠르고 편리하게 이용이 가능하므로 고령자 등 $\Pi$ 기기의 터치가 불편하거나 시각적으로 사용이 어려운 일부 취약계층에게는 편리할 수 있다.

본 연구에서는 스마트시티 환경에서 독거노인을 위한 삶의 질 서비스 향상을 위한 독거노인 맞춤형 인공지능 스피커에 대하여 독거노인들의 지속적 사용의도에 대하여 알아보고자 한다. 고령자 삶의 질 모형을 기반으로 기술수용모형에 적용하여 인지된 유용성과 사용편의성이 지속적 사용의도에 미치는 영향의 관계를 파악하려고 한다.

\section{2. 이론적 배경}

\section{1. 스마트 시티}

스마트 시티는 4 차산업혁명시대와 더불어 등장한 단어로 다양한 정의가 존재하며 국제전기통신연합 (Intemational Telecommunication Union)에서는 스마트 시티의 정의가 116 개가 있다고 하였다(Hwang \& Jang, 2016, 스마트 시티에 대한 정의는 다음과 같다. 스마트 시티는 도시의 문제를 스마트 플랫폼 기반으로 해결하여 삶의 질을 높이고 지속가능성이 있는 도시이다(한국정보화진흥원, 2013). 스마트 시티는 인공지능, 가상현실, 사물인터넷, 빅데이터 등과 같은 4 차산압혁명기반의 기술을 활용한다. 즉 도시공간에 친환경 기반의 ICT 기술을 적용하여 교통, 방범방재, 환경, 에너지, 복지, 주거, 경제 등의 도시기능을 친환경화 효율화를 하고 이를 통하여 도시문제를
해결한다(Lee, 2017; 2018). 스마트시티와 관련된 다양한 선행연구들의 정의를 정리하면 Table 1 과 같다.

Table 1: Definitions of Smart City

\begin{tabular}{|c|c|}
\hline Reference & Definitions \\
\hline $\begin{array}{l}\text { Giffinger et al. } \\
\quad(2007)\end{array}$ & $\begin{array}{l}\text { Future-oriented city in terms of economy, people, } \\
\text { governance, mobility, environment and life based } \\
\text { on given city conditions and conscious } \\
\text { independent citizens }\end{array}$ \\
\hline $\begin{array}{l}\text { Harrison et al. } \\
\quad(2010)\end{array}$ & $\begin{array}{l}\text { A city that maximizes the collective child of the } \\
\text { city by connecting physical infrastructure, } \\
\text { information and communication infrastructure, } \\
\text { social infrastructure, and business infrastructure }\end{array}$ \\
\hline Washburn (2010) & $\begin{array}{l}\text { A city that uses digital technology to provide } \\
\text { better public services for its citizens, uses } \\
\text { resources more efficiently, reduces its } \\
\text { environmental impact, and combines digital } \\
\text { technology with existing networks and services } \\
\text { to increase efficiency for residents and businesses }\end{array}$ \\
\hline $\begin{array}{l}\text { Marsal-Llacuna et } \\
\text { al. (2014) }\end{array}$ & $\begin{array}{l}\text { Cities that use IT technologies to improve urban } \\
\text { performance to provide more efficient services to } \\
\text { citizens, optimize infrastructure, increase } \\
\text { collaboration among different economic entities, } \\
\text { and create innovative business models in the } \\
\text { public and private sectors. }\end{array}$ \\
\hline $\begin{array}{l}\text { National } \\
\text { Information } \\
\text { Society Agency } \\
\text { (2013) }\end{array}$ & $\begin{array}{l}\text { A city that improves the quality of life and } \\
\text { sustainability of citizens by solving various city } \\
\text { problems by applying smart platform }\end{array}$ \\
\hline $\begin{array}{l}\text { British Standards } \\
\text { Institution (2015) }\end{array}$ & $\begin{array}{l}\text { A city that not only reinforces connectivity by } \\
\text { using digital media such as smartphones and } \\
\text { tablets, but also collects and provides real-time } \\
\text { information using various sensors to solve the } \\
\text { needs of cities and citizens. }\end{array}$ \\
\hline
\end{tabular}

스마트시티에 대한 정의를 좀더 상세하게 살펴보면 성장기반의 목적 측면 스마트시티와 스마트한 기술 등을 활용하는 수단측면의 스마트시티로 구분할 수 있다. 목적 측면의 스마트시티는 도시를 시가 수립한 목표에 도달하도록 하는 것을 스마트 시티라고 보는 관점과 도시 구성원들과 시가 함께 의미 및 기능을 결합하여 요구를 도출하고 체감결과를 예측하여 정의하는 시민측면의 스마트시티가 있다. 이를 좀더 상세하게 분석하면 차별화된 서비스를 제공을 스마트시티로 정의하는 서비스 관점과 도시의 구조 변화의 특징으로 정의하는 구조적 관점이 있다. 이러한 차별적 특성은 Table 2 에서 간략하게 정리하였다.

최근에는 수단적 측면의 개념정의가 더 주목을 받고, 그 중에서도 구조적 개념정의가 강조되고 있다. 그리고 이러한 정의내에서 삶의 질, 이동성 등을 강조하는 시민관점의 개념정의가 주목받고 있다. 이러한 스마트 시티의 최종 목적은 시민들의 삶의 질 제고에 있기 때문에 시민적 관점에서 강조하는 시민들의 삶의 질을 제고시키기 위한 스마트시티가 가장 주목받지 않을 수 없다. 따라서 이 연구는 목적적시민적 관점의 시각에서 사회적 취약계층 그 중에서 독거노인의 삶의 
질 서비스를 높이기 위한 기술의 수용도 조사를 실시하고자 한다. 구체적으로는 독거노인들의 삶의 질 향상을 위한 플랫폼으로서 인공지능 스피커 역할이 독거노인들의 해당제품에 대한 수용도에 대한 조사를 통해 독거노인을 위한 삶의 질 개선 서비스로써의 인공지능 스피커 개발 시 우선시하고 고려해야 할 사항이 무엇인지 확인해보려 한다.

Table 2: Concept of Smart City

\begin{tabular}{|c|c|c|c|}
\hline \multirow{2}{*}{$\begin{array}{c}\text { Purpose } \\
\text { perspective }\end{array}$} & \multirow{2}{*}{$\begin{array}{l}\text { Cities that } \\
\text { drive } \\
\text { smart } \\
\text { growth }\end{array}$} & $\begin{array}{c}\text { City } \\
\text { perspective }\end{array}$ & $\begin{array}{l}\text { Cities with Independent } \\
\text { Units Reaching Specific } \\
\text { Development Goals }\end{array}$ \\
\hline & & $\begin{array}{c}\text { Citizen } \\
\text { perspective }\end{array}$ & $\begin{array}{l}\text { City where the members } \\
\text { of the city feel }\end{array}$ \\
\hline \multirow{2}{*}{$\begin{array}{l}\text { Instrumental } \\
\text { perspective }\end{array}$} & \multirow{2}{*}{$\begin{array}{c}\text { City } \\
\text { utilizing } \\
\text { smart way }\end{array}$} & $\begin{array}{l}\text { Service- } \\
\text { oriented }\end{array}$ & $\begin{array}{c}\text { Cities providing } \\
\text { differentiated services }\end{array}$ \\
\hline & & $\begin{array}{l}\text { Structure } \\
\text { center }\end{array}$ & $\begin{array}{l}\text { City with structural } \\
\text { features as a platform }\end{array}$ \\
\hline
\end{tabular}

\section{2. 기술수용도 모형이론}

기술수용모델(technology acceptance mode)은 정보시스템 분야에서 정보시스템의 도입과 수용을 설명하는 강력한 이론 중 하나이다(Sohn, Choi, \& Hwang, 2011). Davis 등에 의해 1989 년에 처음으로 소개된 기술수용모델은 정보시스템에 대한 사용 의도를 인지된 유용성과 인지된 용이성으로 설명한다(Davis et al, 1989). 인지된 유용성은 정보시스템이 일의 성과를 높일 수 있다고 믿는 정도를 뜻하며, 인지된 용이성은 정보시스템을 이용하는데 노력으로부터 자유로워질 수 있는 정도를 의미한다(Davis et al, 1989; Venkatesh, 2000; Sohn et al, 2011; Lee, 2015). 정보시스템이 일에 도움이 되고 사용이 쉽다면 정보시스템에 대한 태도와 사용의도가 긍정적이라는 것이 기술수용모델의 주장이다(Davis et al, 1989; Wang et al, 2006).

기술수용모델은 많은 학자들에 의해 연구되고 확장되어 왔다. 초기의 기술수용모델은 업무 지원정보시스템을 대상으로 함으로써 정보시스템의 기능적인 면에만 초점을 맞췄었다. 그러나 다양한 디지털 기술이 발달하고 정보시스템 이용 목적이 다양해짐에 따라 인지된 유용성(perceived enjoyment)과 같은 내재적 요인을 정보시스템 수용의 새로운 영향 요인으로 연구하여 왔다(Sohn et al, 2011). 많은 정보시스템이 실용적 가치(utilitanian value)와 함께 오락적 기능과 같은 쾌락적 가치(hedonic value)에도 관심을 기울이고 있기 때문이다Sohn et $\mathrm{al}$, 2011).

그러나 TAM 에서 사용자의 인지요인(지각된 유용성과 지각된 용이성)들은 시스템 특성과 같은 외부변수에 의해 시스템 수용형태가 달라진다고 말하고 있다(Davis, 1993; Venkatesh \& Davis, 2000). 따라서 TAM 에서 외부변수 파악은 사용자가 시스템 수용에 대한 설명력을
보다 향상시킬 수 있다(Davis, 1993; Venkatesh \& Davis, 2000). 대표적인 외부변수로는 시스템 특성, 사용자 특성, 조직 구조 등과 같은 것이다(Davis et al., 1989).

정보시스템은 지금까지 TAM 의 주 연구 대상이었던 업무관련 혹은 개인관련 사용자 $\Pi$ 기술과는 다른 특성을 가지고 있다. 따라서 인공지능기반 스피커 수용에 대한 연구에서 사용자 특성에 대한 고려는 중요하다.

본 연구의 대상 정보시스템인 인공지능 스피커는 독거노인의 삶의 질 향상이라는 일차적 기능이 주 목적이지만, 동시에 인간적이고 친근한 대화 인터페이스를 통해 유용함과 사용하기 쉬움의 가치를 제공한다. 따라서, 인공지능스피커의 수용의도를 분석함에 있어서 Davis et al. (1992)의 기술수용모델을 채택하여 연구를 수행하였다.

\section{3. 독거노인의 삶의 질}

노화는 질병과는 관계없이 시간의 흐름에 따라 자연스럽게 발생하는 신체적 기능의 쇠퇴 현상이다. 그러나 노년기에는 이러한 자연스러운 노화로 인한 신체적 변화 뿐만 아니라 은퇴로 인한 사회적 역할의 상실과 경제적 어려움, 자녀의 독립과 배우자나 가까운 지인들의 죽음 등 다양한 정신적, 사회적 변화를 겪는다(Bowling, 2005). 특히, 생명연장 과학기술의 발전으로 인해 늘어난 노년기는 신체적, 정신적, 사회적, 경제적 결핍을 연장시킬 수 있다는 우려와 함께(Gundry, 2019) 인간다운 삶을 유지하기 위한 개인의 적응을 요구한다. 이러한 의미에서 인구 고령화는 삶의 질과 연결하여 고려해야 한다는 주장은 어느 때보다 설득력을 발휘하고 있다(Bowling, 2005; Gundry, 2019).

삶의 질이란 한 개인이 처한 문화와 가치 체계 속에서 자신의 관심, 기대, 목표, 규범 등에 비추어 자신이 위치하는 삶의 수준에 대한 지각(WHOQOL Group, 1994). 이는 일종의 심리적인 개념으로 자신의 주요한 욕구와 목표 등이 얼마나 충족되었는지에 대한 주관적인 인식 수준이라고 할 수 있다(Frisch, 1998). 또한, 삶의 질은 단일한 척도로 파악할 수 없으며, 건강과 신체 기능 수준, 심리적 안녕감, 사회적 관계의 질과 교류 정도, 재정적 여건, 자율성, 물리적 환경 등 다양한 삶의 영역을 포괄하는 다차원적 변인이다(Bowling, 2005). 따라서, 노인의 삶의 질을 파악하기 위해서는 건강, 안전, 재정, 대인관계 등 다양한 요인을 고려할 필요가 있다.

특히 노년기의 독거는 삶의 질을 낮추는 주된 영향 요인으로 알려져 있다. 자녀의 독립, 배우자와의 별거 및 사별 등 노년기 가족 구조의 변화로 인한 독거는 노년기의 다양한 신체적, 정신적 어려움과 긴밀한 관련을 맺고 있다(Km, 2011). 노인의 삶의 질을 평가하기 위해 신체적 건강, 심리적 건강, 사회적 관계 및 경제수준, 물리적 환경 등 다차원적인 하위 영역이 제안된 바 있다Lee, $\mathrm{Km}, \mathrm{Ko}, \mathrm{Ku}$, Kwon \& Km, 
2003). 특히 독거노인의 삶의 질에 대한 구조 모형 분석 연구에서는 삶의 질에 대한 영향 변인으로 신체기능, 일상생활활동, 사회활동 참여, 경제활동 참여, 정신건강 등 다차원적 요인들이 제시된 바 있다(Lee, 2019). 이러한 영향 요인들은 일반적인 노인들과 다르지 않지만, 독거노인의 경우 위와 같은 요인의 부정적인 영향력은 더욱 심각해질 수 있다. 먼저 신체 기능의 변화는 그 자체로 삶의 질을 낮추는 원인인 동시에, 일상생활을 수행하는데 제한을 가져와 삶의 질을 급격히 감소시킨다. 그런데, 독거노인의 경우 신체적으로 건강하지 못하게 되면 일상생활활동 기능이 원활하지 못하게 되어 삶의 질을 유지하는 안전판은 급격히 해체된다. 특히 독거노인은 동거인의 부재로 인해 일상상활에서 도움을 받을 수 있는 사회적지지 체계가 불완전하다(Russell \& Taylor, 2009). 독거노인이 처한 사회적 고립의 위험성은 혹서, 혹한 등 기후 변화, 화재나 낙상과 같은 안전사고 등 위급 상황에서 생존의 가능성을 낮춘다. 또한 이러한 지지의 결핍은 사회적 관계의 질을 또한 낮춘다. 즉 대화 상대의 결핍과 같은 사회적 관계의 상실과 정서적 교감의 단절을 야기하여 삶의 질을 현저히 낮추게 된다Nzabona, Ntozi, \& Rutaremwa, 2016). 신체적 기능, 일상생활활동 수준의 저하, 대인관계 및 사회활동의 결핍은 독거노인들의 외로움과 우울감을 가중시킨다(Choi \& Park, 2009). 한편, 사회활동과 경제활동에의 참여는 노인의 심리적 사회적 건강을 유지시키는 중요한 보호요인으로 알려져 있다(Moon \& Km, 2018). 사회 참여 수준이 높은 노인일수록 삶의 만족감이 높으며(Seok \& Jang, 2016), 독거노인의 경우 사회참여 기간과 빈도가 높을수록 우울 유병률이 낮은 것으로 나타났다.(Nam \& Jung, 2011). 또한 경제활동 참여는 노년기 삶의 질을 향상시키는 가장 큰 영향요인으로 주목되었으며(Baker, Cahalin, Gerst \& Bur, 2005; HaO, 2008), 경제활동에 참여하는 독거노인일수록 삶의 만족도가 높은 것으로 나타났다(Kang \& Yoon, 2017).

이상의 선행연구를 바탕으로 본 연구에서는 독거노인 삶의 질에 대한 선행 연구들의 제안을 토대로 독거노인의 삶의 질에 대한 주요 구성요인으로 신체건강, 일상생활, 안전, 대인간 소통, 경제생활 참여, 여가활동 참여 등 여섯 개의 하위 영역을 설정하였다.

독거노인 삶의 질 향상을 위해 본 연구에서 설정한 대상 정보 시스템인 인공지능 스피커의 사용과 관련하여 다음과 같은 고령자의 인지, 신체, 감각적 특징을 고려할 필요가 있다. 고령자는 일반적 신체기능(감각인지신체), 특히 시력과 청력, 기억력 등의 저하와 더불어 근력의 저하가 일어난다. 시각은 노안 증상으로 인하여 눈이 쉽게 피로해지고 앞이 침침해지는 증상을 보이며, 청각은 고음을 듣기 어려워져 주변 상황을 판단하는데 있어 어려움과 차가 지나가는 소리나, 벨 소리 등을 듣기 어려워진다. 또한, 근력의 저하로 인하여 스마트폰 사용에서 손으로 집는 행위에 대한 어려움을 느끼고, 좁은 곳을 터치하는 정확도가 떨어지게 된다. 하지만, 주변 상황을 분석하는데 필요한 인지기능에 있어서 자연음성보다 기계 음성을 인지하는 것은
불편함을 겪지 않는다. 현재 출시되고 있는 다양한 $\Pi$ 기기들의 대부분은 고령자의 신체적 특성을 제대로 고려하지 않고 있기 때문에 사용에 있어 어려움을 느낄 가능성이 있다(Chung \& Kim, 2015). 반면에 인공지능 스피커의 경우 음성기반으로 명령을 내리고 답을 하기 때문에 사용하는데 있어 불편함을 크게 느끼지 않는다.

\section{4. 인공지능 스피커}

인공지능 스피커는 음성인식 기술을 포함한 인공지능시스템 모듈을 탑재한 스피커이며 사용자의 목소리를 인식하여 명령을 수행하는 인공지능 비서이다Roh \& Choi, 2018). 사람들이 인공지능 스피커를 가장 많이 활용하는 분야는 음악 플랫폼을 활용한 노래듣기이며, 일정을 관리하거나, 날씨를 실시간으로 전달받거나, 교통상황, 환율은 기본으로 음성을 통하여 내가 원하는 정보를 실시간으로 전달해 들을 수 있다. 인공지능 스피커가 가지는 가장 큰 강점은 복잡한 인터페이스를 통한 입력이 필요없이 자연어 기반의 사람의 목소리만으로 명령을 내리고 제어를 할 수 있다는 점이다Cho \& Lee, 2019).

Canalys(2018)의 연구에서는 한국의 인공지능 스피커 판매량은 세계 3 위로 큰 시장을 형성하고 있으며 아직도 빠른 성장세를 보이고 있다. 해당 연구에서는 2018 년 한국의 인공지능 스피커 단말기는 약 300 만대에 달할 것으로 전망하였다.

이에 인공지능 스피커를 연구, 제품을 생산하는 국내 기업들은 제품의 성능 향상과 서비스 확대를 위해 노력하고 있다.

인공지능 스피커가 처음 개발되었을 때는 대기업통신사 위주로 개발되었으며 음악과 기초 생활정보 제공의 기능이 있었다면, 현재는 개인비서, 금융, 쇼핑, 학습, 운세 등 우리 삶과 밀접하게 연관된 다양한 기능을 제공하고 있다. 또한, 화자인식 기술을 통하여 사용자의 정보를 스스로 인식하여 맞춤형 응대를 하며, 카메라를 통해 화자의 운동량, 건강 상태 등의 체크가 가능하다. 이외에도 인공지능 스피커를 편의점과 호텔에 설치하여 서비스 영역의 확대를 꾀하고 있다. 이와 관련하여 학계에서도 인공지능 스피커의 기술 개발 및 서비스 확장에 관한 연구들이 이루어지고 있다(Marakakis, Kondylakis, \& Anis, 2016).

또한 과거 초창기의 인공지능 스피커 관련하여 주로 기술 개발과 서비스 확장관련 연구를 했다면, 이제는 인공지능 스피커 수용성, 사용자의 경험, 사용자의 활용 행동의도에 관한 연구들이 시작되고 있다(Yong \& Yoon, 2018; Yang, 2017). 그러나 이러한 연구들은 특정 사용층의 수용 요인을 파악하기에는 한계가 있다. 하지만 특정 목적을 가진 보다 세분화된 사용자들에 대한 수용성에 대한 연구는 부족한 실정이다.

\section{3. 연구방법}




\section{1. 연구대상}

스마트 시티 기술의 일환으로 개발 예정인 독거노인용 챗봇 기술에 대한 잠재적 사용자의 지각된 기술 수용도를 측정하기 위하여 2019 년 6 월 국토교통부의 스마트시티 챌린지 사업의 후보 지방자치단체로 선정된 경기도 수원시에 거주하는 65 세 이상의 고령자를 대상으로 설문조사를 실시하였다. 수원시의 65 세 이상 고령자 수는 2019년 12 월 말 기준으로 123,647 명으로 전체 시 인구의 $1035 \%$ 이다. 특히, 수원시 팔달구는 수원시가 추진하는 스마트시티 챌린지 사업의 시범지역으로, 팔달구의 65 세 이상 고령자 수는 25,354 명으로 전체 구 인구의 $13.25 \%$ 를 차지하여 수원시의 4 개 구 중에서 고령자 인구 비율이 가장 높은 지역구이다(통계로 보는 수원, 2019 년 12 월 30 일 기준). 본 연구의 설문조사에 응한 유효 사례 수는 74 명으로 응답자의 성비는 여자가 $82.6 \%$, 남자가 $17.4 \%$ 였다. 응답자의 평균 연령은 78.2 세, 표준편차는 6.18 세, 응답자의 최소연령은 65 세, 최대연령은 97 세였다. 응답자의 생애 주된 직업 분포로는 일반사무직·판매.영업직은 $7.1 \%$, 자영업.수공업.운송 사업은 $14.3 \%$, 전문직.관리직은 $12.9 \%$, 주부·무직은 $55.7 \%$, 기계공·트럭 운 전사는 $2.9 \%$, 단순조립공정 근로자는 $2.9 \%$, 막노동·소규모 농사는 $2.9 \%$ 의 분포였다.

응답자들이 보고한 현재 경제생활 만족 수준은 1 5 점 척도에서 평균 3.1, 표준편차 0.94, 현재 건강상태 수준은 평균 3.0 , 표준편차 0.92 로 나타났다.

\section{2. 측정도구}

Table 3: Questionnaire Items

\begin{tabular}{|c|c|c|}
\hline Variables & Items & Source \\
\hline $\begin{array}{l}\text { Perceived } \\
\text { Usefulness }\end{array}$ & $\begin{array}{l}\text { Using Artificial Speaker systems would } \\
\text { increase my ........ } \\
\text { 1.Physical management } \\
\text { 2. Schedule management } \\
\text { 3. Security } \\
\text { 4. Recruiting information } \\
\text { 5.Communication with others } \\
\text { 6.Leisure activity }\end{array}$ & $\begin{array}{l}\text { Davis (1989), } \\
\text { WHOQoL } \\
\text { Group (1994) }\end{array}$ \\
\hline $\begin{array}{l}\text { Perceived } \\
\text { Ease of Use }\end{array}$ & $\begin{array}{l}\text { I think that using Artificial Speaker } \\
\text { systems ........ } \\
\text { 1. Wise } \\
\text { 2.Desirable } \\
\text { 3.Positive }\end{array}$ & Davis (1989) \\
\hline $\begin{array}{l}\text { Attitude } \\
\text { towards Use }\end{array}$ & $\begin{array}{l}\text { Methodology to Using Artificial Speaker } \\
\text { systems are ........ } \\
\text { 1.Not easy } \\
\text { 2.Not hard to learn } \\
\text { 3.Easy to use at any time } \\
\text { 4.Any one can use it. }\end{array}$ & Davis (1989) \\
\hline $\begin{array}{l}\text { Intention to } \\
\text { Use }\end{array}$ & $\begin{array}{l}\text { I think that I would use Artificial } \\
\text { Speaker systems ..... } \\
\text { 1.Continuously } \\
\text { 2.Often } \\
\text { 3.Definitely }\end{array}$ & Davis (1989) \\
\hline
\end{tabular}

본 연구에서 측정되는 구성 개념들은 기존 선행연구에서 신뢰성 타당성이 입증된 것을 바탕으로 Table 3 과 같이 본 연구에 맞게 수정하여 사용하였다. 설문의 모든 항목의 응답은 '전혀 그렇지 않다'에서부터 '매우 그렇다'에 이르는 Likert 7 점 척도로 측정되었으며, 응답자가 높은 점수에 응답할수록 측정 항목을 높게 지각하는 것으로 평가하였다.

Table 4: Convergent validity and internal consistency reliability

\begin{tabular}{|c|c|c|c|}
\hline Constructs & Items & $\begin{array}{c}\text { Factor } \\
\text { loading }\end{array}$ & $\begin{array}{c}\text { Cronbach's } \\
\text { alpha }\end{array}$ \\
\hline \multirow{6}{*}{$\begin{array}{l}\text { Perceived } \\
\text { Usefulness - } \\
\text { Life Quality }\end{array}$} & PULQ1 & 0.87 & \multirow{6}{*}{0.91} \\
\hline & PULQ2 & 0.808 & \\
\hline & PULQ3 & 0.89 & \\
\hline & PULQ4 & 0.721 & \\
\hline & PULQ5 & 0.819 & \\
\hline & PU6 & 0.874 & \\
\hline \multirow{4}{*}{$\begin{array}{l}\text { Perceived Easy } \\
\text { of Use }\end{array}$} & PEOU1 & 0.823 & \multirow{4}{*}{0.855} \\
\hline & PEOU2 & 0.767 & \\
\hline & PEOU3 & 0.849 & \\
\hline & PEOU4 & 0.889 & \\
\hline \multirow{3}{*}{$\begin{array}{l}\text { Attitude } \\
\text { towards Use }\end{array}$} & ATU1 & 0.918 & \multirow{3}{*}{0.924} \\
\hline & ATU2 & 0.944 & \\
\hline & ATU3 & 0.933 & \\
\hline \multirow{3}{*}{ Intention to Use } & ITU1 & 0.928 & \multirow{3}{*}{0.915} \\
\hline & ITU2 & 0.931 & \\
\hline & ITU3 & 0.914 & \\
\hline
\end{tabular}

\section{3. 자극 제시 및 자료 수집 절차}

본 연구의 설문조사 자료 수집을 위해 2019 년 12 월 17 일부터 26 일까지 수원시 팔달구 소재 구립 및 민간 노인복지관 5 개소에서 운영하는 노인복지 프로그램의 참가자를 대상으로 설문조사에 참여하였다. 설문조사는 복지 프로그램 시행 직전 또는 직후에 실시하였으며, 설문조사 당시 운영 중인 프로그램은 노래교실 1 개, 영화관람 2 개, 한글교실 1 개, 실내악연주회 1 개였다. 설문조사를 시작하기에 앞서 노인복지교육 프로그램 담당자의 협조를 통해 연구진과 연구목적을 소개하였으며, 설문조사에 대한 동의서 작성을 안내하였다.

본 연구의 대상 시스템인 인공지능 챗봇에 대한 사용 의도를 평가하기 위하여 독거노인의 챗봇 사용 체험 동영상을 제작하였다. 이 동영상에서는 남성 독거노인 1 명이 주인공으로 수원시 스마트시티 챌린지 사업으로 제작 예정인 인공지능 챗봇과 상호작용하는 장면이 연출되었다. 특히 본 영상은 독거노인의 삶의 질에 관한 선행연구를 바탕으로 독거노인의 삶의 질 구성 요인으로 도출된 신체건강, 
일상생활, 안전, 경제활동 참여, 심리사회 지원, 사회활동 참여 등 6 개 영역에서 인공지능 챗봇을 활용한 사례를 제시하고 있다.

구체적으로 신체건강 관리 장면은 기상 체크와 아침식사 메뉴의 영양에 대한 정보를 제공하고, 일상생활 관리 장면에서는 보건소 방문 시간 등 일정을 관리해주고, 안전 관리 장면은 챗봇이 부억에서 들리는 날카로운 소리를 감지하고 안전 여부를 묻고 119 에 연결하는 장면이 연출되었다. 경제활동 참여 지원 장면은 챗봇이 일자리 정보를 알려주고, 심리사회적 지원 장면은 노인의 전화 상담사 연결을 통해 외로움을 관리해주고, 사회활동 지원 장면은 동호회를 연결해주는 장면이 연출되었다. 영상 시청을 포함한 총 설문조사는 총 30 분 정도 소요되었으며, 노인 프로그램 참가자 중 국문 해독이 어렵거나 설문지 작성에 애로사항이 있으신 분들은 조사에 참여하지 않았다. 설문지는 고령자가 읽기에 적합하도록 한글 16 포인트 이상의 크기로 제작하였으며, 고령 응답자의 설문 문항 이해도를 높이기 위해 각 문항을 별도의 파워포인트 화면으로 제작하여 설문 장소인 강의장 단상 스크린에 빔프로젝터로 제시하여 설문 대상자들에게 한 문항씩 진행자가 설명하면서 응답할 수 있도록 하였다. 설문조사 종료 후 응답자에게는 1 만원 상당의 기념품이 보상으로 제공되었다.

\section{4. 연구결과 및 토론}

본 연구의 실증분석을 위하여 통계패키지 SPSS 25.0 와 SmartPLS 3.0을 이용하였다. 표본의 일반적 특성을 분석하기 위해서 빈도분석을 하였다. 다음으로 설문지의 항목이 도출된 측정변수를 측정하는 데 있어 타당 여부를 확인하기 위해 Varimax 직각회전방법을 통해 요인분석을 시행하였고, 변수들의 신뢰성이 있는지 측정하기 위해 Cronbach's $\alpha$ 계수를 이용하여 신뢰도를 실시하였다.

\section{1 척도 타당성 및 신뢰성 분석}

검증결과 Table 4처럼 요인별 측정항목의 요인분석결과 요인적재치가 0.4 이상의 수치를 보여 측정항목의 타당성이 충분한 것으로 판단되었다. 신뢰도를 분석 결과 Cronbach's $\alpha$ 의 계수는 평균적인 기준치인 0.6 보다 높이 나타남으로써 내적 일관성이 있는 항목으로 구성되어 있음을 보여주어 문제없이 분석에 사용하였다.

\section{2 가설검증}

구조모형분석의 내용은 Figure 1 , Table 5 와 같다. 독거노인들은 삶의 질 영역에 있어 인지된 사용편의성이 인지된 유용성에 강한 영향을 미치는
것으로 나타났다. 다음으로 노인의 삶의 질 영역에 있어 인지된 유용성은 사용에 대한 태도에 영향을 미치는 것으로 나타났다 $\beta=720$, $\mathrm{t}=9.406$ ). 하지만 인지된 사용편의성은 사용에 대한 태도에 영향을 미치지 못하는 것으로 나타났다 $(\beta=.085, \mathrm{t}=.964)$.

다음으로는 사용의도에 영향일 미치는 요인들에 대하여 살펴보면, 먼저 노인의 삶의 질 영역에 있어 인지된 유용성은 사용의도에 약하게 영향을 미치는 것으로 나타났다 $(\beta=338, t=1663)$. 마지막으로 사용에 대한 태도는 사용의도에 약하게 영향을 미치는 것으로 나타났다 $\beta=346$, $\mathrm{t}=1807$ ).

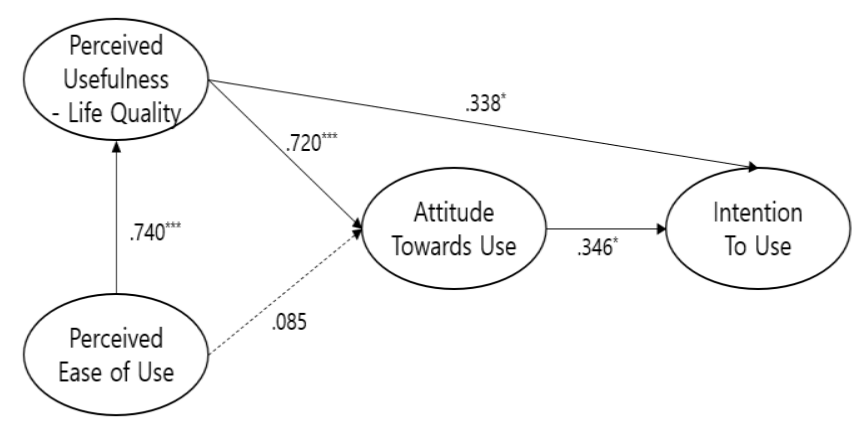

Figure 1: Path Coefficient of SEM

Table 5: Results of Hypothesis Test

\begin{tabular}{|c|c|c|c|c|}
\hline Effects & $\begin{array}{c}\text { Path } \\
\text { coefficient }\end{array}$ & t value & p value & Support \\
\hline $\mathrm{PEOU} \rightarrow \mathrm{PULQ}$ & .740 & 14.832 & $0.000^{* * *}$ & $\mathrm{~S}$ \\
\hline $\mathrm{PULQ} \rightarrow \mathrm{ATU}$ & .720 & 9.406 & $0.000^{* * *}$ & $\mathrm{~S}$ \\
\hline $\mathrm{PEU} \rightarrow \mathrm{ATU}$ & .085 & 0.964 & 0.336 & $\mathrm{NS}$ \\
\hline $\mathrm{PULQ} \rightarrow \mathrm{ITU}$ & .338 & 1.663 & $0.097^{*}$ & PS \\
\hline $\mathrm{ATU} \rightarrow \mathrm{ITU}$ & .346 & 1.807 & $0.071^{*}$ & PS \\
\hline
\end{tabular}

PEOU: Perceived Ease of Use

PULQ: Perceived Usefulness Life Quality

ATU: Attitude towards Use

ITU: Intention to Use

$* * * \mathrm{p}<.01$

$* * \mathrm{p}<.05$

$* \mathrm{p}<.1$

통계분석의 결과로부터 살펴보았을 때 다음과 같은 시사점을 얻을 수 있다. 먼저 독거노인들이 인공지능기반 스피커를 사용하려는 태도가 생기려면 노인들의 삶의 질에 대한 인지된 유용성이 있어야 한다는 점이다. 본 연구에서 제시했던 노인의 삶의 질 6 개 영역 신체건강, 일상생활, 안전, 대인간 소통, 경제생활 참여, 여가활동 참여에 대하여 인공지능 스피커가 도움을 준다라고 느낄 때 사용에 대한 태도가 강력한 인과관계가 형성되는 것을 확인할 수 있었다. 하지만 사용의 용이성은 사용에 대한 태도에 유의미한 인과관계가 나타나지 않았다. 즉, 독거노인들은 사용하기 쉽다고 느끼는 것은 사용에 대한 태도에 
유의미한 영향을 미치지 않았다. 그러나 인공지능 스피커가 사용하기 쉽다고 느끼는 것은 삶의 질을 향상시키는데 도움이 될 것이라고 생각하며 이는 곧 인공지능스피커를 사용하려는 태도가 생겨 간접적인 효과를 찾아볼 수 있었다. 또한 사용에 대한 태도는 사용의도에 약하게 영향을 주는 것을 확인할 수 있었다. 마지막으로 삶의 질에 대한 인지된 유용성은 사용의도에 직접적인 관계에 있어 약하게 영향을 미치는 것으로 나타났다.

\section{5. 결론}

\section{1 시사점}

본 연구는 스마트 시트 환경에서 독거 노인이라는 특정 사용자 층을 위한 삶의 질 향상을 위한 서비스 환경에 대한 기술수용에 대한 연구를 진행하였다. 최근 4 차 산업혁명시대 스마트 시티가 각광받고 있으며 스마트 시티의 근간을 이루는 기술이 우리 생활에 밀접하게 다가와 있다. 하지만 대부분 일반적 시민의 관점에서 이루어진 연구가 대부분이다. 본 연구에서는 독거 노인을 위한 삶의 질 향상을 위하여 인공지능 스피커가 독거 노인들에게 어떠한 영향을 미치는지 살펴보았다.

다음으로는 인지된 사용성을 기존의 척도가 아닌 독거노인이라는 특정 사용층에 맞추어 정의하고 새로운 척도로 정리하였다. 기존의 기술수용모형에서는 인지된 유용성의 문항을 제시하였다면 본 연구에서는 삶의 질 향상이라는 측면에서 $\mathrm{WHO}$ 가 정의한 삶의 질 영역과, 측정도구를 활용하여 삶의 질 관련 인지된 유용성 척도를 제시하였다.

\section{2 한계점 및 향후 연구계획}

본 연구가 가지는 한계점은 다음과 같다. 구조방정식 모형을 검증하기 위하여 필요로 하는 데이터의 수가 충분하지 못하였다. 본 연구에서는 인지능력이 떨어지는 노인분들을 대상으로 실제 인공지능 스피커를 경험할 수 있도록 하며 그것이 자신의 삶의 질에 어떻게 영향을 줄지 설문을 통하여 측정하도록 하였다. 하지만 초고령 연령대를 다수 포함한 연구집단 특성상 인공지능 서비스에 대한 인지, 설문지에 대한 이해, 답을 쓰는 방법에 대한 이해 부족으로 인하여 설문지 작성을 지원하는 보조인력을 다수 투입하였다.
그럼에도 불구하고 많은 데이터를 수집하는 데는 한계가 있었으며 구조방정식 분석을 수행하는데 부족함은 없었으나 충분하지는 못했다. 다음으로는 데이터가 특정 지역에서만 추출된 부분이다. 본 연구는 정부사업을 통해 수행된 연구이며 이에 수원시 팔달구 지역의 독거노인만을 대상으로 연구를 진행하였다. 따라서 지역별 특성에 따른 노인들의 삶의 질의 특성에 대한 효과를 컨트롤 하지 못하였다. 다만 수원시 팔달구의 경우 고령화가 빠르게 진행되는 지역 중 하나이며 이러한 특성의 지자체에서는 적용이 가능할 것으로 판단된다. 따라서 추후 연구에서는 연구의 목적에 따라 지역 분포를 고려한 데이터 수집이 필요하다.

\section{References}

Baker, L.A., Cahalin, L.P., Gerst, K., \& Bur, J.A. (2005). Productive activities and subjective well-being among older adults: The influence of number of activities and time commitment. Social Indicators Research, 73, 431-458.

Bowling, A. (2005). Ageing well: Quality of life in old age. New York: McGraw-Hill Education.

Canalys. (2018). Google beats Amazon to first place in smart speaker market. Retrieved December 18, 2019, from https://www.canalys.com/newsroom/google-beats-amazon-tofirst-place-in-smart-speaker-market.

Cho, D. H., \& Lee, Y. J. (2019). Factors that Affect User Satisfaction toward Continuous Usage of AI Speakers Focusing on The Mediation Effect of Emotional Attachment -. Journal of Korea Design Forum, 24(2), 87-100.

Chung, J. Y., \& Kim, H. S. (2015). Grounded Theory Analysis on The Elderly's Use of Automated Transaction Machines. Archives of Design Research, 28(4), 119-133.

Davis, F. D. (1989). Perceived usefulness, perceived ease of use, and user acceptance of information technology, MIS Quarterly, 13(3), 319-340.

Davis, F. D., Bagozzi, R.P., \& Warshaw, P. R. (1992). Extrinsic and intrinsic motivation to use computers in the workplace, Journal of Applied Social Psychology, 22, 1111- 1132.

Frisch, M. B. (1998). Quality of life therapy and assessment in health care. Clinical Psychology: Science and practice, 5(1), $19-40$.

Gundry, S. R. (2019). The longevity paradox: How to die young at a ripe old age. HarperCollins Publishers, New York, NY.

Hao, Y. (2008). Productive activities and psychological well-being among older adults. The Journal of Gerontology: SOCIAL SCIENCES, 63B(2), S64-S72.

Heijden, H. (2003). Factors influencing the usage of websites: the case of a generic portal in The Netherlands. Information and Management, 40(6), 541-549.

Kang, J. P., \& Yoon, J. Y. (2017). A Study on Multi-level Models in life satisfaction of Elderly Living alone: Moderating Effect of Elderly's Leisure Activity and Social Support. Journal of Digital Convergence, 15(5), 89-98. 
Kim, J. G. (2011). The Impact of Family Type on Health Behavior of Elderly People. Korean Journal of Gerontological Social Welfare, 51, 35-55.

Koufaris, M. (2002). Applying the Technology Acceptance Model and Flow Theory to Online Consumer Behavior. Information Systems Research, 13(2), 205-223.

Lee, H. S., Kim, D. K., Ko, H. J., Ku, H. M., Kwon, E. J., \& Kim, J. H. (2003). The Standardization of Geriatric Quality of Life scale. Korean Journal of Clinical Psychology, 22(4), 859-881.

Lee, J. K. (2015) A Study on the Determinants of Acceptance Intention in Customized Smart Advertising: With a Focus a Group of College Students. Journal of Speech, Media \& Communication Association, 26, 85-114.

Lee, Y. M. (2019). Structural Equation Model of Quality of Life of Older People living alone. Doctoral thesis is Seoul National University.

Marakakis, E., Kondylakis, H., \& Aris, P. (2016). APANTISIS: A Greek Question-Answering System for Knowledge-Base Exploration. Strategic Innovative Marketing, Springer proceedings in Business and Economic book series, 501-510.

Min. S. J., Kim, H. J., \& Song, G. H. (2017). An Exploratory Study on Determinants of Acceptance of Chatbot Using Integrated Technology Acceptance Theory (UTAUT). Korea Technology Innovation Society Proceedings of Spring Conference, 623-643.

Moon, J. W., \& Kim, Y. G. (2001). Extending the TAM for a World-Wide-Web context. Information and Management, 38(4), 217-230

Moon, J. H., \& Kim, D. H. (2019). Factors Influencing Life Satisfaction in Elderly Living Alone. Journal of Korea Multimedia Society, 18(1), 44-54

Nam, K., \& Jung, E. (2011). the influence of social activity and social support perceived by elderly women living alone on their quality of life: Focusing on the mediating effect of depression and death-anxiety. Journal of Welfare for the Aged, $52,325-348$.

Nzabona, A., Ntozi, J., \& Rutaremwa, G. (2016). Loneliness among older persons in Uganda: Examining social, economic and demographic risk factors. Ageing \& Society, 36(4), 860888 .
Park. D. A. (2017) A Study on Conversational Public Administration Service of the Chatbot Based on Artificial Intelligence, Journal of Korea Multimedia Society, 20(8), 1347-1356.

Roh, M. J., \& Choy, M. K. (2018). The Effect of Personal Innovativeness on the Adoption of A.I. Speakers: The Moderating Effect of Purse String Control. Journal of Business Research, 33(1), 195-230.

Russell, D., \& Taylor, J. (2009). Living alone and depressive symptoms: The influence of gender, physical disability, and social support among Hispanic and non-Hispanic older adults. Journal of Gerontology Series B: Psychological Science and Social Sciences, 64(1), 95-104.

Sohn, S. H., Choi, Y. J., \& Hwang, H. S. (2011) Understanding Acceptance of Smartphone among Early Adopters Using Extended Technology Acceptance Model, Korean Journal of Journalism \& Communication Studies, 55(2), 227-251.

Seok, J. E., \& Jang E. J. (2016). The Effect of Social Relationship Resource by Gender on the Life Satisfaction of Elderly Living Alone. Korean Journal of Gerontological Social Welfare, 71(2), 321-349.

Teo, T. S. H., Lim, V. K. G, \& Lai, R. Y. C. (1999). Intrinsic and extrinsic motivation in Internet usage. The International Journal of Management Science, 27, 25-37.

Venkatesh, V., \& Davis, F. D. (2000). A theoretical extension of the technology acceptance model: four longitudinal field studies, Management Science, 46(2), 186-204.

WHOQoL Group, (1994). The development of the World Health Organization quality of life assessment instrument. (the WHOQoL) Quality of life assessment: International perspectives: Springer, 41-57.

Yan, M., Castro, P., Cheng, P., \& Ishakian, V. (2016). Building a Chatbot with Serverless Computing. Proceedings of the 1st International Workshop on Mashups of Things and APIs, 5.

Yang, H. T. (2017). User Acceptance of Virtual Personal Assistant Devices: An Extended Perspective of Perceived Value. Journal of the Korea Contents Association, 17(10), 179-189.

Yong, A. R., \& Yun, J. Y. (2018). A Study on the Improvement of the Voice of the Virtual Assistant Service for the Elderly, Proceedings of HCI Korea 2018, 726-729. 